\title{
A ATUAÇÃO DE TÉCNICOS DE SELEÇÕES NACIONAIS DE MODALIDADES COLETIVAS: ELEMENTOS INDICADORES PARA UM ESTUDO SOBRE EXCELÊNCIA NO ESPORTE
}

Hermes Ferreira Balbino

Pedro Jose Winterstein

\section{Resumo}

A competência do técnico e relevante diante do amplo escopo de variáveis presentes no contexto esportivo bem como no processo de treinamento, em que a atuação do técnico pode determinar o sucesso de um processo ou seu fracasso. A atividade do técnico abrange um conjunto de conhecimentos que se referem aos campos: conceitual, comunicativo, capacidade técnica e dos relacionamentos pessoais. Este estudo, a partir da investigação dos referenciais teóricos de autores da Pedagogia do Esporte, da Teoria do Treinamento e da Psicologia, e da utilização de analise argumentativa, tem como objetivo delinear o conceito de excelência no trabalho do técnico esportivo de modalidades coletivas.

\section{Palavras-Chave}

Competência; Técnico; Excelência; Jogos esportivos coletivos.

\section{THE TECHNICIAN'S OF NATIONAL SELECTIONS OF COLECTIVE MODALITIES: INDICATIVE: ELEMENTS FOR A STUDY ON EXCELLENCY IN THE SPORT}

Hermes Ferreira Balbino

Pedro José Winterstein

\begin{abstract}
The coach's competence is relevant, before the wide scope of variables present in the sport context, as well as in the training process, in which the coach's performance may determine the process' success or failure. Coach's activities include a package of knowledge that refers to the conceptual, communicative, technical capacity and personal relation fields. This study is based on a research of the authors of Sport Pedagogy, Training Theory and Psychology on its theoretical references, as well as the use of the argumentative analysis, with the aim of building the concept of the sport coach's work excellence.
\end{abstract}

\section{Key-Words}

Competence; Coach; Excellence; Team sports games 


\section{INTRODUÇÃO}

A partir do fato expresso por resultados bem sucedidos alcançados por seleções nacionais de modalidades coletivas em eventos esportivos intemacionais, considera-se que o processo de preparação no Esporte Profissional, assim definido por Paes (2000) exige profissionais qualificados para exercer tal função, sendo que o nível das competições intemacionais e os resultados atingidos pelas seleções brasileiras das modalidades coletivas, aqui consideradas voleibol, futebol, futsal, basquetebol e handebol, demonstram o desempenho desses técnicos em competições com alto nível de exigência. O conhecimento utilizado por técnicos esportivos do Esporte Profissional, agentes da ciência aplicada, permanece ainda por ser explorado no campo da pesquisa acadêmica. Isto posto, os elementos desenvolvidos neste estudo inicial podem se compor como ponto de partida para estudos futuros que objetivem descrever estratégias de aplicação do conhecimento cientifico em situações de treinamento esportivo dos jogos esportivos coletivos, para os profissionais e acadêmicos da área. Um dos propósitos deste estudo introdutório e apontar, na possibilidade de um estudo futuro, elementos indicadores para uma investigação que leve em conta: a horizontalidade, no que se refere a padrões de estratégias encontradas no grupo dos técnicos; a sua verticalidade, significada pelas estratégias singulares da atuação e procedimentos de técnicos das seleções nacionais de modalidades coletivas em processos de treinamento e competição, na medida em que podem se constituir como referenciais para a construção e manifestação de trabalhos qualificados e reconhecidos no contexto do Esporte.

\section{OBJETIVO}

O objetivo deste artigo e delinear o conceito de Excelência para atuação de técnicos esportivos de modalidades coletivas, a partir da constituição de um corpo teórico referenciado em autores da Teoria do Treinamento Esportivo, da Pedagogia do Esporte e da Psicologia, formando assim um conjunto de elementos indicadores para estudo sobre a Excelência no Esporte.

\section{METODOLOGIA}

Para o desenvolvimento, construção, e delimitação do campo conceitual indicado, a partir da investigação da literatura relativa a temática representada em sua configuração por quatro pontos estruturais, será usada a analise argumentativa de Toulmin (LIAKOPOULOS, 2002), com o propósito de interpretar e associar os referenciais teóricos elencados, e atender o objetivo indicado. 


\section{DESENVOLVIMENTO DO TEMA}

O conhecimento teórico e metodológico na especificidade da área do treinamento esportivo tem estimulado nos treinadores o desenvolvimento de diversas competências para condução de praticas para otimizar intervenções nas ações de treinamento, jogos e competições (BALBINO, 2005). A partir desta colocação, inferimos aqui a construção do conceito de excelência na atuação do técnico, a partir da argumentação evocada por quatro pontos estruturais, que seguem:

\section{O ESPORTE PROFESSIONAL EXIGE DE SEUS PARTICIPANTES ALTO NÍVEL DE DESEMPENHO E PRODUZ MODELOS QUE SÃO IMITADOS}

O Esporte e reconhecido como um fenômeno de múltiplos significados, universalmente crescente, economicamente em expansão e recente, sendo considerado por Paes (2000) um patrimônio cultural da humanidade. Para Cagigal (1981), e a atividade do homem completo, sendo que seus significados tornaram-se mais complexos ao longo da Historia da humanidade, desde os primeiros relates da Grécia antiga de Platão e Aristóteles ate o surgimento do Esporte Moderno, em finais do século XIX. Na evolução histórica do Esporte, estaríamos vivendo hoje a fase denominada por Cagigal (1981) de Esporte Contemporâneo, que exibe duas direções. A primeira e a do Esporte Espetáculo, que e marcado pela alta competição, movido pela mídia, tende ao profissionalismo, exige sensacionalismo, evoca presença de heróis, e que e determinado pela Ciência e Tecnologia. A outra direção, a do Esporte Praxis, e determinado pela pratica consciente e equilibrada para o cidadão comum, pode ser praticado em qualquer espaço e é aberto a todos.

O fenômeno Esporte mostra-se intensamente vivenciado neste inicio de século XXI, tendo como exemplos de sua ampla manifestação os Jogos Olímpicos, realizados a cada quatro anos e os Campeonatos Mundiais das diversas modalidades reconhecidas pelo Comitê Olimpico Intemacional, que se realizam também a cada quatro anos, de maneira a não coincidir com o evento olimpico. Respeitando esse tipo de organização do calendário esportivo que e integrado as programações da Mídia tem-se eventos esportivos internacionais de caráter competitivo anualmente.

Paes (2000) denomina de Esporte Professional quando este fenômeno contempla questões relativas a competição e ao espetáculo esportivo. Neste âmbito, desempenhos vitoriosos têm constante destaque no contexto esportivo, projetando os esportistas que participam das conquistas. A necessidade de exposição do patrocinador esportivo na mídia atraves de eventos, de equipes ou de investimentos individuais nos atletas faz com que o Esporte Profissional se constitua em ambiente de alto desempenho de seus 
participantes, pois o desempenho vitorioso permite uma associação positiva da marca patrocinadora com o patrocinado, seja ele uma equipe ou um esportista. Os resultados destacados são produtos de um amplo conjunto de fatores: metodologia de treinamento adequada, estímulos de condições psicológicas próprias aos desafios esportivos, investimentos de patrocinadores, dedicação de atletas e comissão técnica em tempo integral de trabalho, entre outros. Tendo em vista sua presença cotidiana na mídia, Paes (2000) afirma que o Esporte mostra-se como um fenômeno presente de forma intensa na vida de muitas pessoas, tendo implicações no campo da Saúde, da Educacao, do Lazer, do Trabalho, da Política, da Cultura, do Marketing e da Moda.

$\mathrm{Na}$ interface do fenômeno Esporte com as pessoas que se relacionam com ele, esta o Efeito Imitação, identificado por Cagigal (1981) como o fenômeno em que indivíduos ou comunidades imitam seus modelos esportivos, tanto em comportamentos que são manifestos no campo de competição como em comportamentos que são manifestos em situações de vida cotidiana. A partir do exposto, os participantes do Esporte Profissional tem desempenho mediante alto nível de exigência, junto a responsabilidade social com a comunidade em que estão inseridos, conferindo-lhe caráter que considera e ultrapassa os resultados bem sucedidos de conquista de medalhas ou campeonatos, e alcança o campo dos valores humanos que são transmitidos pelos participantes das conquistas.

Os Jogos Esportivos Coletivos, dentro de suas características, se constituem em ambiente para manifestação das competências dos técnicos.

O jogo esportivo coletivo, uma categoria do Esporte, e definido por Teodorescu (2003) como microssistema social, que acontece dentro de um piano físico de ações conjuntas, na condução do objeto de jogo em direção a um alvo determinado, onde a qualidade de relacionamentos entre os companheiros de uma mesma equipe se opõe a um outro sistema de relacionamentos de adversários, em ação conjunta para formar a idéia de jogo, em relação não hostil.

Os jogos esportivos coletivos, como modalidades integrantes do fenômeno Esporte, tem se manifestado com destaque no cenário esportivo nacional, desde o final do século XIX com o Futebol, e no decorrer do século XX, com outras modalidades como o Basquetebol, o Voleibol, o Futsal e o Handebol. No âmbito nacional, sua expressividade tem se confirmado com a participação significativa das seleções nacionais em eventos internacionais, com destaque para diversas conquistas de posições expressivas em eventos oficiais das federações internacionais responsáveis pelas modalidades. O sucesso e a significância do processo de treinamento desenvolvido são comprovados pela Constancia de resultados 
bem sucedidos das equipes nacionais de modalidades coletivas em Campeonatos Mundiais nos últimos vinte anos, nas edições dos Jogos Olímpicos de Barcelona em 1992, Atlanta em1996, Sydney em 2000 e Atenas em 2004 e Jogos Pan-americanos do Rio de Janeiro em 2007. Técnicos brasileiros de modalidades coletivas tem seus nomes ligados as conquistas das seleções nacionais e tornados como responsáveis diretos pelo sucesso das equipes, e citamos alguns exemplos: do basquetebol Miguel Angelo da Luz, Antonio Carlos Barbosa e Maria Helena Cardoso, do voleibol Jose Roberto Guimarães e Bernardo Rezende, do futebol Carlos Alberto Parreira e Luiz Felipe Scolari.

Garganta (1998) destaca a imprevisibilidade e a aleatoriedade das ações de jogo entre os elementos construtores do contexto dos JECs, e que são significativos para sua caracterização e entendimento, e a necessidade de múltiplas competências do treinador e do atleta para interagir com situações assim caracterizadas neste ambiente especifico. A partir dai, o técnico esportivo pode trabalhar com os pressupostos que sustentam seus procedimentos e considerar a flexibilidade dos mesmos para integrar as diversas competências do individuo que constantemente interagem com o complexo sistema de praticas de preparação, o jogo formal e suas exigências. Em estudo de Balbino (2005), com treinadores de seleções brasileiras de modalidades esportivas coletivas, mostrou-se que a ação pedagógica produz intervenções que o planejamento metodológico do treinamento não prediz, ou seja, apresenta respostas e soluções para situações em praticas de treinamento que são imprevisíveis e aleatórias.

O técnico das modalidades coletivas dos jogos esportivos manifesta múltiplas competências no processo de preparação e competição esportiva.

O processo de preparação, ou treinamento esportivo, e fundamental na obtenção de resultados de êxito no Esporte. Matveev (1997) define o treinamento esportivo como um processo complexo, em que o desempenho final do atleta ou da equipe e resultado da síntese de diversos fatores. Bompa (2002) ressalta que o sucesso do treinamento se refere inicialmente ao domínio das informações das Ciências do Esporte, e também a competência e habilidade que o técnico esportivo demonstra ao tratar o conjunto de diversas variáveis presentes no ambiente de treinamento, nas suas dimensões físicas, psicológicas e sociais.

Gardner et al. (2004) estudaram competências humanas e o âmbito de suas manifestacoes atraves da inteligência e demonstram acreditar que cada um de nos abriga dentro de si capacidades de manifestar esse tipo diferenciado de estratégias da mente. Desta maneira, ter a compreensão de mentes de pessoas 
sujeitas a um contexto de alto nível de exigência nos permitiria dar uma contribuição importante a sociedade e satisfazer aspectos da realização pessoal.

No que se refere as teorias psicológicas, outro autor a ser considerado para esta concepção de excelência, tendo em conta sua visão sistemática de desempenho humano em alto nível de exigência, e Mihaly Csikszentmihalyi (2004), que se lança a considerar a dimensão de excelência manifesta em termos de uma serie de características que se sobrepõem. Tomamos como referencial para nossas considerações a atuação e os resultados obtidos pelas equipes nacionais de modalidades coletivas, lideradas por técnicos esportivos que tem em sua historia profissional desempenho vitorioso, manifesto por conquistas em competições internacionais, citados anteriormente.

Matveev (1997), Verkhoshanski (2001) e Bompa (2002) concordam em seus estudos sobre a importância da competência do técnico em considerar o amplo escopo de variáveis presentes no contexto esportivo e utilizá-lo no processo de treinamento. Segundo os autores, a atuação do treinador pode determinar o sucesso de um processo ou seu fracasso. Para entender o contexto em que o treinamento e aplicado, e necessário destacar características relevantes dos jogos esportivos coletivos (JECs).

Em seu estudo, Balbino (2005) afirma que o técnico das modalidades coletivas manifesta múltiplas competências em sua atuação pedagógica no treino esportivo, mediante as exigências deste complexo contexto. Revela-se assim um conhecimento empírico da logística de treino, bem como na condução do processo ao longo de uma temporada e no controle da preparação esportiva em si, no que se refere as capacidades físicas, técnicas, táticas e psicológicas. Este tipo de contexto não e previsível, conferindo característica de complexidade ao processo de preparação para competições (Balbino, 2005).

Tomando o treinamento como um campo de praticas onde a pedagogia se faz presente, Bompa (2002, p. 5) afirma que atraves do treinamento desportivo, "um treinador lidera, organiza, planeja o treinamento e educa o atleta." A dimensão educativa do treinamento esta presente pela necessidade de se adaptar aos estímulos provocados pelo complexo jogo, competição, treinamento, relacionamentos com companheiros de equipe, adversários, técnicos, mídia, dirigentes, familiares. Matveev (1997) define o treinamento como fenômeno pedagógico e aponta para os aprendizados atraves do desporto, em junção com a obtenção de elevados resultados. Bompa (2002) determina que o aparecimento de resultados da excelência física combina harmoniosamente os fatores refinamento espiritual, pureza moral e perfeição física. 
Mesquita (2000) determina que o técnico esportivo, nesta visão cientifica do processo de treinamento, deve possuir um conjunto diversificado de habilidades para interagir com os elementos que compõem o ambiente do esporte profissional, o que exige o desenvolvimento de um amplo espectro de competências. Aqui tratamos competência com o conceito que lhe atribui Perrenoud (2000), ou seja, a capacidade que o individuo possui de mobilizar diversos recursos cognitivos para enfrentar um tipo de situações. Mesquita (2000) preconiza que a atividade do técnico abrange um conjunto de conhecimentos que se referem aos campos: conceitual, que diz respeito ao domínio e conhecimento das questões das ciências do esporte e da modalidade em que trabalha; comunicativo, que se refere a transmissão adequada de idéias e as capacidades de comunicação não-verbal; capacidade técnica que diz respeito a organização e condução do processo de treinamento. Acrescentamos aqui o campo dos relacionamentos pessoais, que se refere aos tipos de relações a se estabelecer com os integrantes do grupo, apontado por Weinberg \& Gould (2001) no destaque que dão a importância da liderança em um processo de grupo em modalidades esportivas coletivas. Os autores afirmam que uma vez otimizadas as competências do treinador nessa dimensão, conduzem o grupo a manifestar comportamentos mais efetivos em competições.

Balbino (2005) considera que o treinador deve manifestar competências e habilidades para tratar constantemente com as situações-problema de características referentes aos diversos domínios de inteligência (Gardner, 2004), presentes em jogos e treinamentos. Gardner (1994) menciona em sua Teoria das Inteligências Múltiplas as competências relativas a processamento de informações em determinado ambiente. Em sua definição de inteligência, Gardner (1994) coloca que inteligência, como sistema complexo, significa um potencial biopsicológico, que processa informações a fim de resolver problemas ou criar novos contextos de problemas ou produtos que sirvam para uma comunidade. Podemos entender essas aptidões que o técnico esportivo deve ter e sua capacidade de atuar com apoio de seu conjunto de conhecimentos, como indicam os autores anteriormente citados (MATVEEV, 1997; MESQUITA, 2000; VERKHOSHANSKI, 2001; BOMPA, 2002) como referentes aos domínios das inteligências ou competências determinadas por Gardner (1994). 


\section{O TÉCNICO ESPORTIVO DO ESPORTE PROFISSIONAL ATUA E PRODUZ RESULTADOS MEDIANTE ALTO NIVEL DE EXIGÊNCIA.}

O técnico esportivo, tido como um líder que opera processos junto a equipes de desempenho esportivo, no contexto do Esporte Profissional, determinado para este estudo, conduz o grupo que dirige a produzir resultados. Aqui, tomamos o fato de o técnico muitas vezes apresentar ao atleta uma nova maneira de pensar sobre um assunto conhecido, pois o ambiente de jogo e treinamento esportivo e imprevisível e aleatório (Garganta, 1998), e os elementos humanos se relacionam de acordo com um ambiente de interpessoalidade. No caso, o técnico esportivo, programa e executa treinamentos que sao aplicados em determinado contexto. Sua atuação pedagógica produz, mediante desempenho de alto nível de exigência, determinados resultados, que consideramos um trabalho caracterizado pela excelência. Ao tomar-se o propósito de estudar a excelência da atuação pedagógica no treinamento esportivo, consideramos inicialmente o estudo da inteligência por Gardner (2004), que justifica o estudo da mudança dos comportamentos dos indivíduos pela mudança de estratégias mentais, pois, para ele, a mudança esta na representação mental do individuo, a maneira pela qual a pessoa percebe, codifica, retem e acessa informações.

\section{RESULTADO: DA INTERPRETAÇÃO E ASSOCIAÇÃO A CONSTITUIÇÃO DO CONCEITO}

Ao interpretar e associar os elementos indicativos dos referenciais teóricos elencados, o conceito de excelência na atuação do técnico esportivo se constitui na medida em que este:

Possui múltiplas competências, para tratar com um contexto de múltiplos elementos que compõem o desempenho no Esporte, e das exigências que recaem sobre os atletas, como determinado por Balbino (2005), em estudo com técnicos esportivos das modalidades coletivas. Competência envolve conhecimento especifico, que e aplicada em algum lugar, o que evoca relacionar-se com algum contexto.

Poe em pratica tais competências em ambiente de alto nível de exigência e desempenho e obtém resultados bem sucedidos, no domínio especifico para manifestação de suas habilidades. Na concepção de Gardner (1994) e Gardner et al. (2004), os autores apontam para a possibilidade da presença da excelência quando ha interação dinâmica entre o individuo em si, com seus talentos e objetivos; o domínio ou disciplina específicos nos quais o individuo escolheu trabalhar; e o campo, ou seja, o conjunto de pessoas e instituições que expressam julgamentos acerca da qualidade do trabalho. Transmite valores humanos durante o processo de treinamento e competição. Para este outro aspecto do que 
denominamos a constituição do conceito de Excelência para este estudo, significa que alem de possuir conhecimento especifico sobre o processo de treinamento e competição, e também conseguir responder positivamente aos níveis de exigência, que, embora seja altos e expressos pelos resultados de vitória, possa atraves de sua atuação manter a presença dos valores humanos durante o processo. Desta maneira, a atuação do técnico significa aqui um trabalho de qualidade técnica, que expressa os resultados a que se propõe. Em teoria apresentada por Cagigal (1981), alem da relevância e expressividade do resultado, os esportistas, tanto atletas como treinadores, são agentes do Efeito Imitação. A partir deste fenômeno apontado por Cagigal (1981), inferimos que o esportista tem responsabilidade social, pelo impacto que seus comportamentos, sejam na esfera esportiva ou fora dela, provocam nos indivíduos de uma comunidade, atraves da ação da mídia ao evidenciar o Esporte, em ação conjunta com o Marketing Esportivo.

\section{CONSIDERAÇÕES FINAIS}

E relevante salientar que a busca de modelos bem sucedidos na esfera competitiva do Esporte nos remete a considerar os processos de treinamento de equipes nacionais que obtiveram resultados destacados, e provocaram impacto na comunidade esportiva. Da mesma maneira, pelos valores atribuídos ao o fenômeno Esporte durante o transcorrer de sua historia, a excelência da atuação do treinador esta em um primeiro momento delimitada pelo desempenho de alto nível, que apresenta resultados manifestos pelas conquistas vitoriosas de jogos ou campeonatos, e que pela diversidade e transcendência de seus significados reclama a presença da ética, ao se conferir responsabilidade social aos esportistas que atingem resultados expressivos no esporte, formando assim um conjunto de elementos indicadores para estudo sobre a Excelência no Esporte.

Ao se considerar esses elementos, um estudo mais profundo do contexto de treinamento e competição das seleções nacionais das modalidades coletivas se faz necessário, em torno da atuação e dos procedimentos dos técnicos de seleções nacionais de modalidades coletivas, na medida em que podem se configurar como referenciais para a constituição e manifestação da excelência na Pedagogia do Treinamento Esportivo.

\section{REFERÊNCIAS}

BALBINO, H. F. Pedagogia do treinamento: método, procedimentos pedagógicos e as múltiplas competências do técnico nos jogos desportivos coletivos. 2005. Tese (Doutorado) - Faculdade de Educação Física, Universidade Estadual de Campinas, Campinas, 2005. 
BOMPA, T. Periodização: teoria e metodologia do treinamento. Sao Paulo: Phorte, 2002.

CAGIGAL, J. M. Oh deporte! anatomia de um gigante. Valladolid: Minon, 1981.

GARDNER, H. Estruturas da mente: a teoria das inteligências múltiplas. Porto Alegre: Artes Medicas Sul, 1994.

. CSIKSZENTMIHALYI, M. ; DAMON, W. Trabalho qualificado: quando a excelência e a ética se encontram. Porto Alegre: Artmed/Bookman, 2004.

GARGANTA, J. Para uma teoria dos jogos desportivos coletivos. In: GRAQA, A. ; OLIVEIRA, J. (Eds.). O ensino dos jogos desportivos coletivos. Lisboa: Universidade do Porto, 1998. p. 11-25.

LIAKOPOULOS, M. Analise argumentativa. In: BAUER, M.W.; GASKELL, G. Pesquisa qualitativa com texto, imagem e som. Petrópolis: Vozes, 2002. p. 218- 243

MATVEEV, L. Treino desportivo: metodologia e planejamento. Guarulhos: Phorte, 1997.

MESQUITA, I. A pedagogia do treino: a formação em jogos desportivos coletivos. Lisboa: Livros Horizonte, 2000.

PAES, R. R. Esporte competitivo e espetáculo esportivo. In: MOREIRA, W. W.; SIMOES, R. Fenômeno esportivo no inicio de um novo milênio. Piracicaba: Editora da Unimep, 2000. p. 33-39.

PERRENOUD, P. Dez novas competências para ensinar. Porto Alegre: Artmed, 2000.

TEODORESCUJ. Problemas de teoria e metodologia dos jogos desportivos. Lisboa: Horizonte, 2003. VERKHOSHANSKI, Y. Treinamento desportivo: teoria e metodologia. Porto Alegre: Artmed, 2001.

WEINBERG, R.S.; GOULD, D. Psicologia do esporte e do exercício. 2. ed. Porto Alegre: Artmed, 2001 


\section{Hermes Ferreira Balbino}

Faculdade de Educação Física - UNICAMP

\section{Pedro Jose Winterstein}

Faculdade de Educação Física - UNICAMP

\section{Referência do artigo:}

\section{ABNT}

BALBINO, H. F., WINTERSTEIN, P. J. A atuação de técnicos de seleções nacionais de modalidades coletivas: elementos indicadores para um estudo sobre excelência no esporte. Conexões, v. 6, p. 585-595, 2008.

\section{APA}

Balbino, H. F., \& Winterstein, P. J. (2008) A atuação de técnicos de seleções nacionais de modalidades coletivas: elementos indicadores para um estudo sobre excelência no esporte. Conexões, 6, 585-595.

\section{VANCOUVER}

Balbino HF, Winterstein PJ. A atuação de técnicos de seleções nacionais de modalidades coletivas: elementos indicadores para um estudo sobre excelência no esporte. Conexões, 2008; 6: 585-595. 